شبيه سازى تجربى ابعاد بياز رطوبتى بافتهاى مختلف خاى

ندا خانمحمدى و سينا بشارت

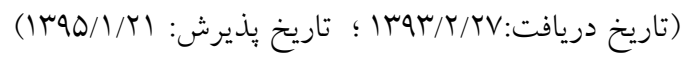

جكيده

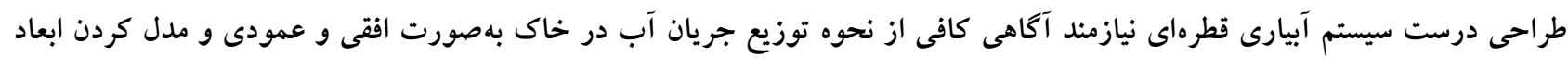

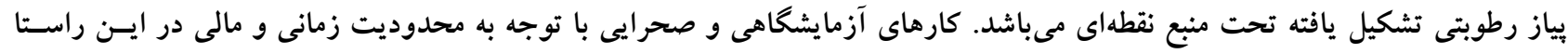

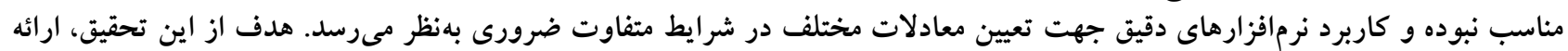

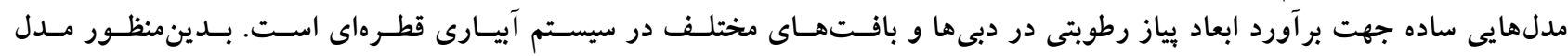

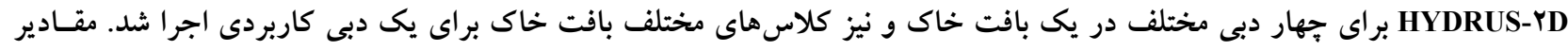

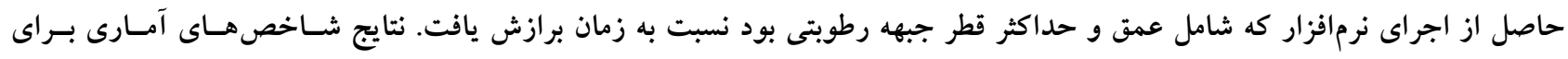

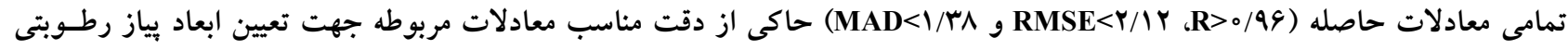

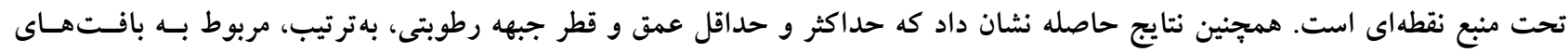
شنى لومى و سيلت مى باشد.

كلمات كليدى: آبيارى قطرهاى، ابعاد يياز رطوبتى، مدل HYDRUS-2D 
خـانمحمــى و همكــاران (r) نشـان داد كـه HYDRUS-rD

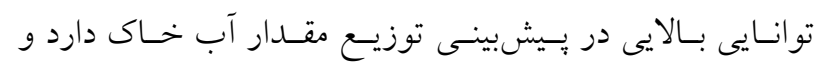

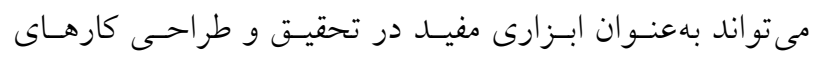
مديريتى آبيارى قطرهاى مورد استفاده قرار كيرد.

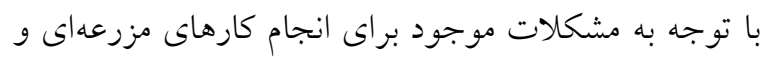

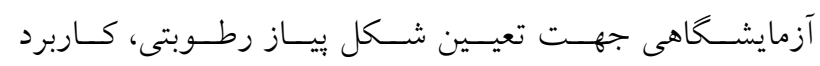

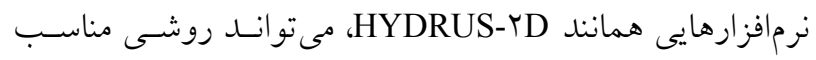

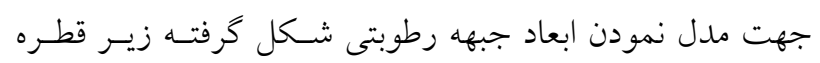

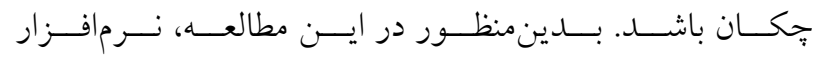
جهت تعيين معادلات تجربى برآورد ابعاد ييساز

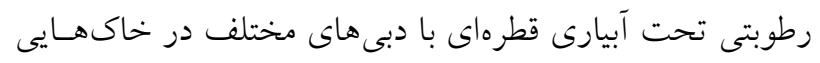

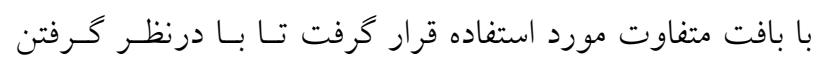

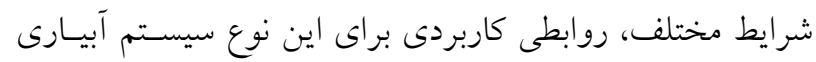

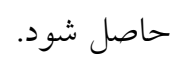

\section{مواد و روشها}

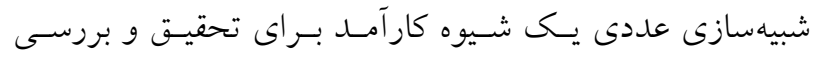

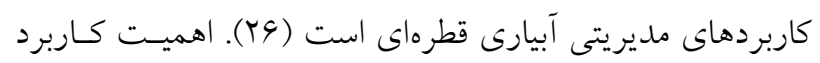

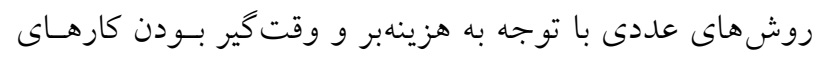

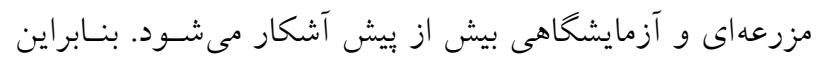

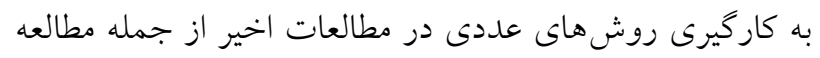

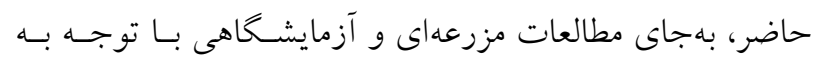
محدوديت آنها، امرى منطقى بوده و سر آغاز نخاهى نو به مسائل

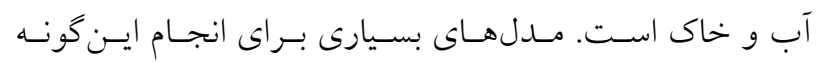

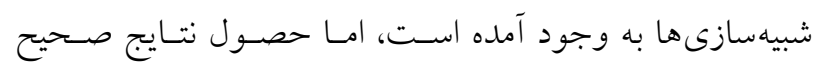

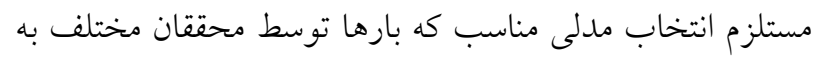

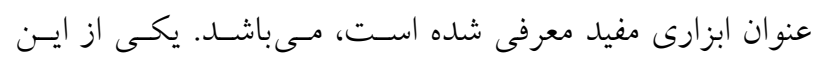

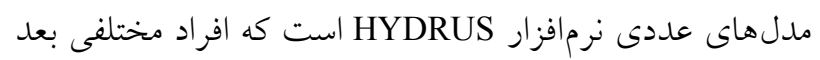

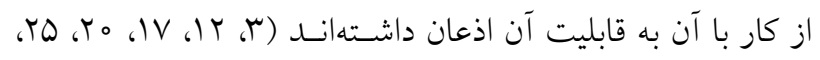

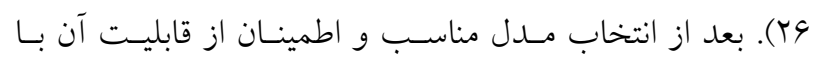

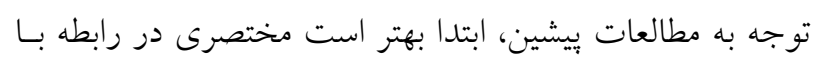

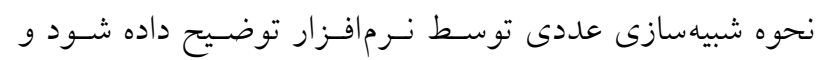

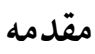

در ميان روشهاى آبيـارى تحـت فشـار روش آبيـارى قطرهاى

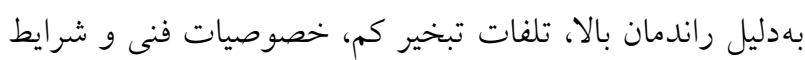

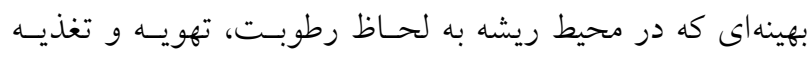

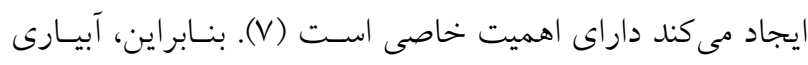

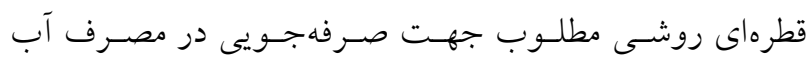
كشاورزى قلمداد مى گردد و استخراج روابط تعيسين ابعـاد ييساز

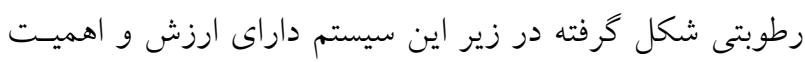

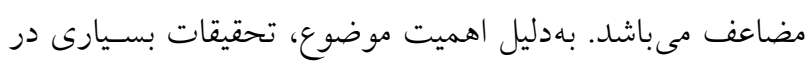

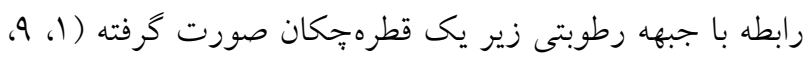

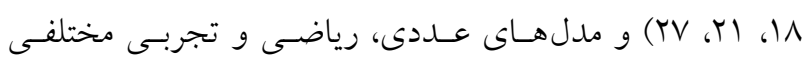

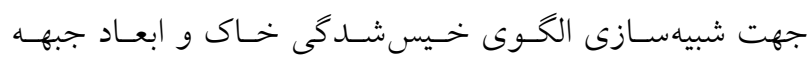

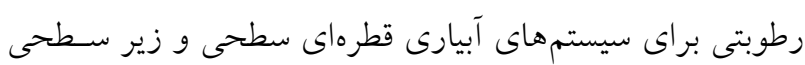

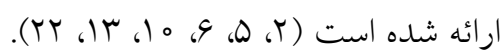

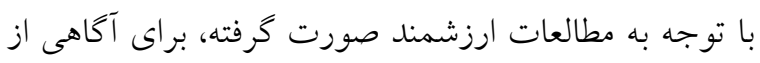

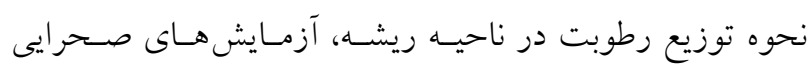

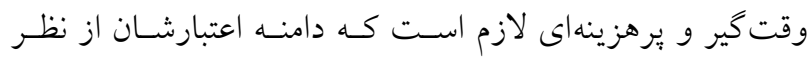

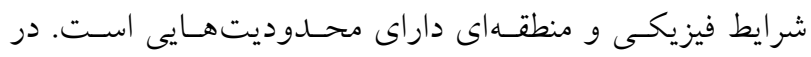

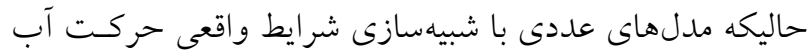

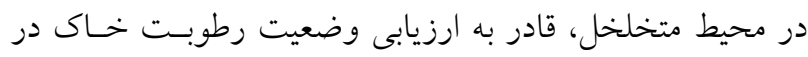

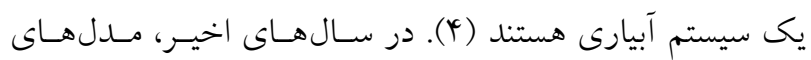

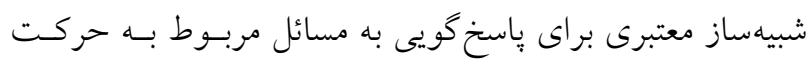

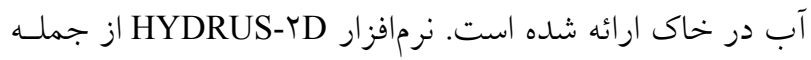

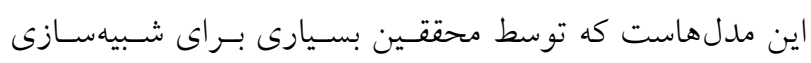

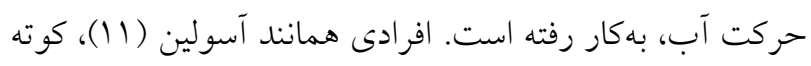

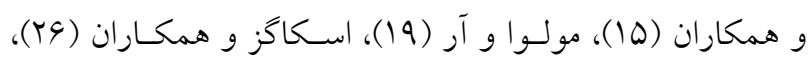

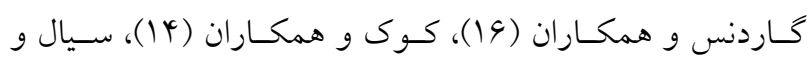

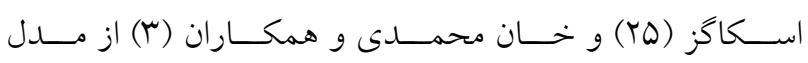

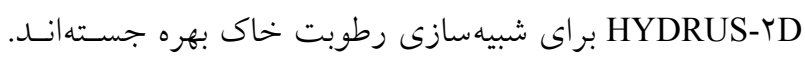

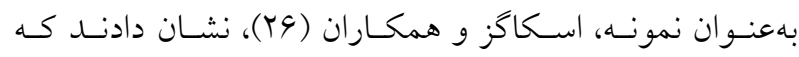

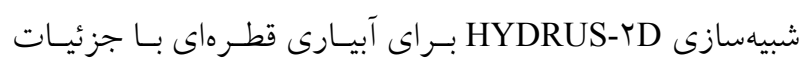

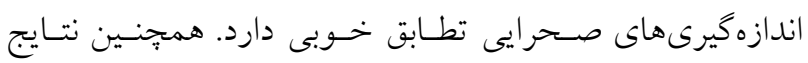


براى هر r ا كلاس بافت خاك تعبيهشده در آن براى دبى ثابـت

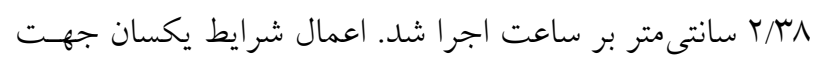

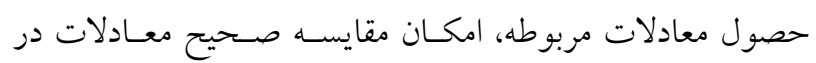
شرايط كاربردى را فراهم خواهد آورد.

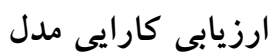

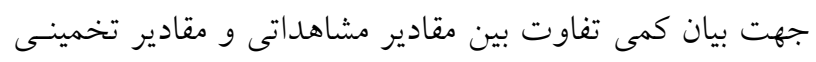

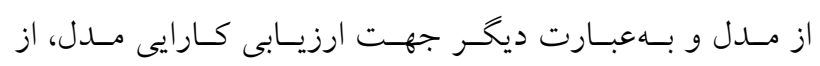
شاخص هاى خطا هم جون جذر ميانخين مربعات خطا (RMSE)

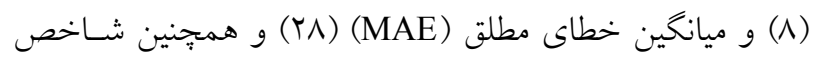
همبستخى (R) (Tr) كه بهصورت زير بيان مسىشـوند، استففاده كثته است.

$$
\begin{aligned}
& \text { RMSE }=\sqrt{\frac{\sum_{i=1}^{n}(X-\hat{X})^{r}}{n}} \\
& \text { MAE }=\frac{1}{n} \sum_{i=1}^{n}|X-\hat{X}|
\end{aligned}
$$

$$
R=\frac{\left[\sum_{i=1}^{n}(\hat{X}-\hat{\bar{X}})(X-\bar{X})\right]}{\sqrt{\sum_{i=1}^{n}(\hat{X}-\hat{\bar{X}})^{r} \times \sum_{i=1}^{n}(X-\bar{X})^{r}}}
$$

كه در آنها، n اندازه نمونه، X مقادير تخمينى از فرمولهـاى

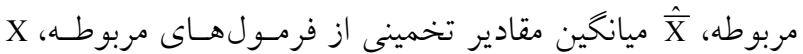
مقادير مشاهداتى و X Xيانكين مقادير مشاهداتى مى مياشند.

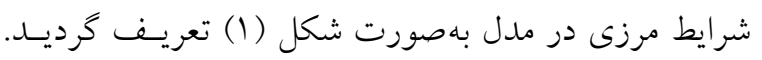

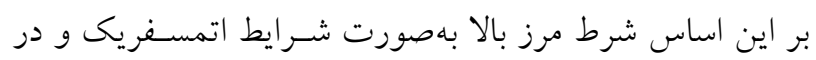

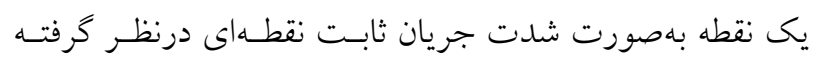

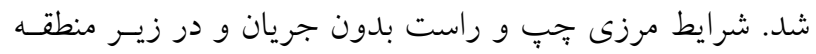
شبيهسازى بهصورت زهكش آزاد مدنظر قرار گرفت

\section{نتايج و بحث}

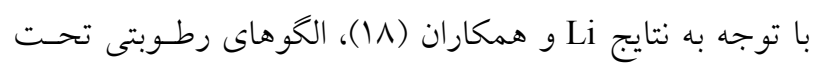

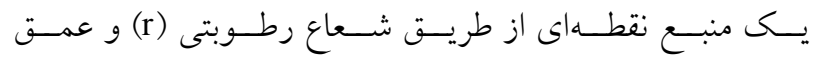

سبس روش كار بيان گردد.

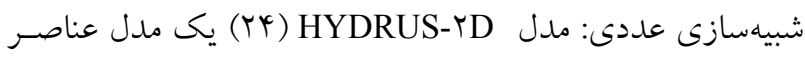

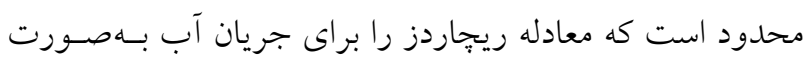

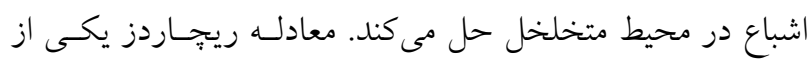

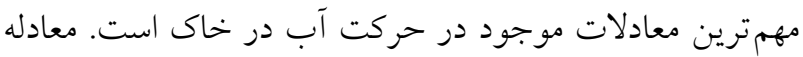

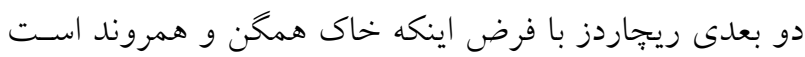

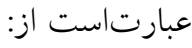

$\frac{\partial \theta}{\partial \mathrm{t}}=\frac{\partial}{\partial \mathrm{x}}\left[\mathrm{K}(\mathrm{h}) \frac{\partial \mathrm{h}}{\partial \mathrm{x}}\right]+\frac{\partial}{\partial \mathrm{z}}\left[\mathrm{K}(\mathrm{h}) \frac{\partial \mathrm{h}}{\partial \mathrm{z}}+\mathrm{K}(\mathrm{h})\right]$ كه در آن، $\theta$ مقدار حجمى آب، h بار فشـارى آب خـاك،

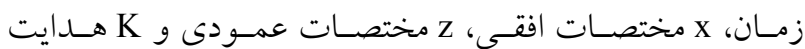

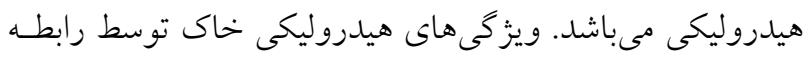

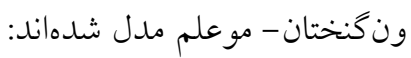

$\theta(h)=\left\{\theta_{r}+\frac{\theta_{\mathrm{S}}-\theta_{\mathrm{r}}}{\left(1+|\alpha \mathrm{h}|^{\mathrm{n}}\right)^{\mathrm{m}}} \mathrm{h}<0\right.$

$\mathrm{K}(\mathrm{h})=\mathrm{K}_{\mathrm{S}} \mathrm{S}_{\mathrm{e}}{ }^{1}\left[1-\left(1-\mathrm{S}_{\mathrm{e}}{ }^{1 / \mathrm{m}}\right)^{\mathrm{m}}\right]^{2}$

$\mathrm{S}_{\mathrm{e}}=\frac{\theta-\theta_{\mathrm{r}}}{\theta_{\mathrm{S}}-\theta_{\mathrm{r}}}, \quad \mathrm{m}=1-1 / \mathrm{n}$

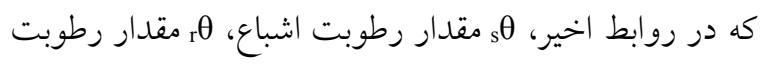

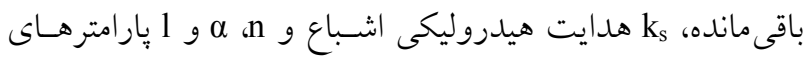

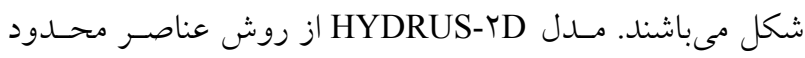
براى حل معادلات ا تا ب استفاده مى كند. (Galerkin-type)

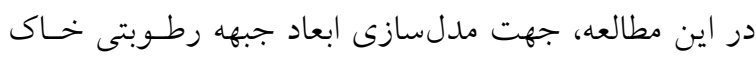

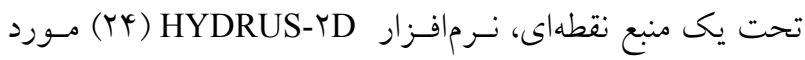
استفاده قرار كرفت. در اين شبيهسازى فقط قسمت راسـت بيـاز رطوبتى درنظر كرفته شــــ مـشبنــى مرزهـا در روش عناصـر

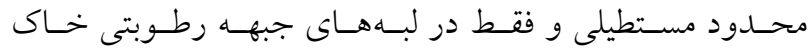
بهصورت مثلثى درنظر كرفتـه شـــ لولـه قطرهزجــان در مـرز بهصورت يك نيم دايره در قسـمت مـرزى بـالا وارد نــرمافـزار

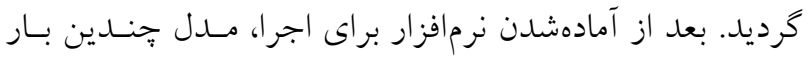

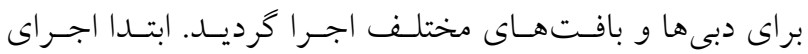

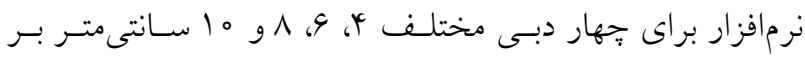
ساعت بدون تغيير بافت خاك صورت گرفت. سـبس نـرمافـزار 

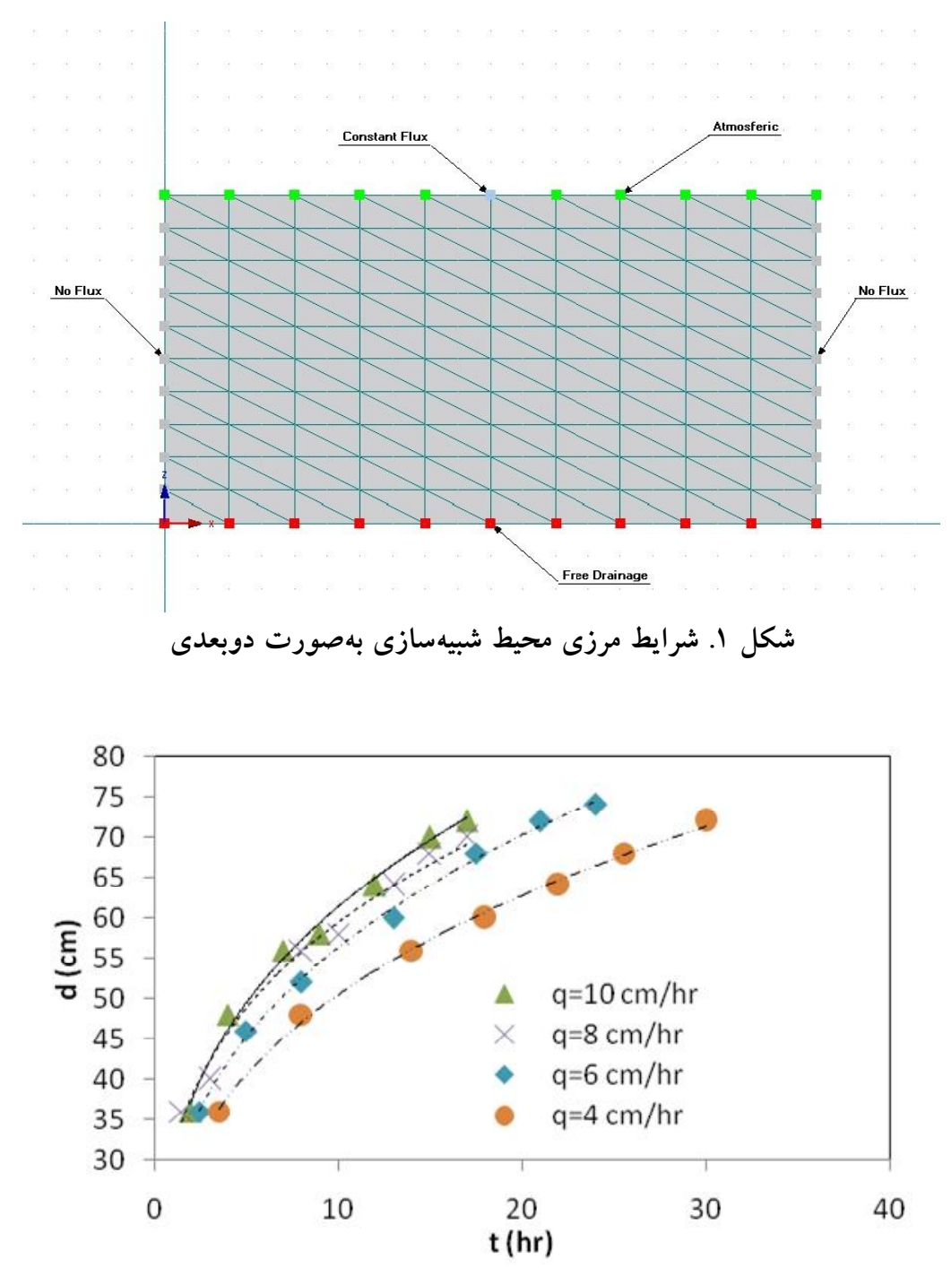

شكل r. تغييرات حداكثر قطر بياز رطوبتى نسبت به زمان براى دبىهاى مختلف

الف) معادله تعيين حداكثر قطر بيــاز رطـوبتى در دبسىهـاى مختلف

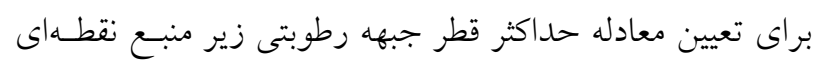

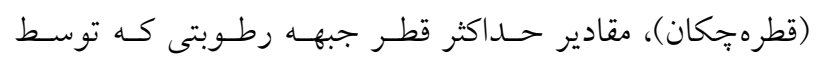

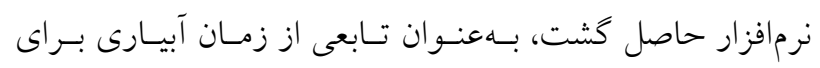
دبى هاى مختلف ترسيم شد (شكل r Y).

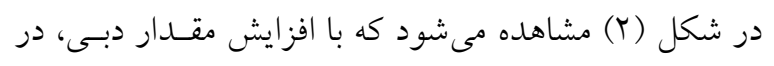

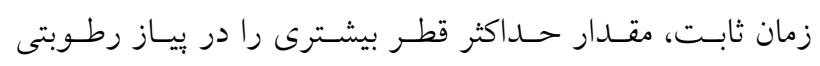

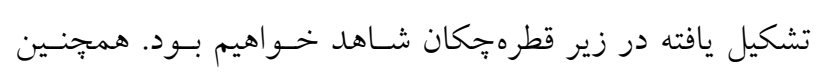

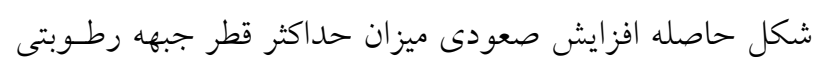

خيس شدىى (z) مشخص مىشوند بنابراين، بررسى حداكثر قطر

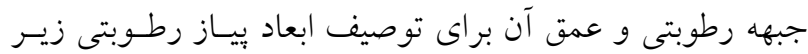

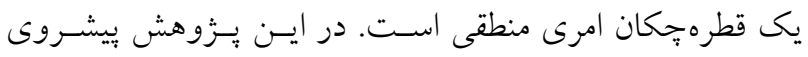

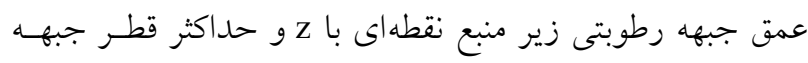

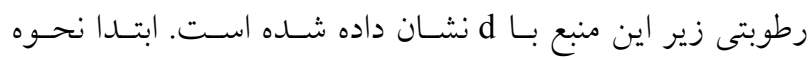

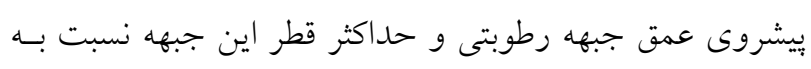

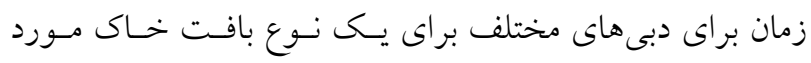

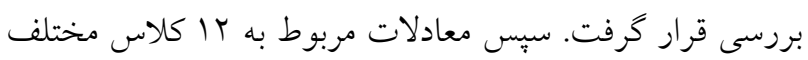

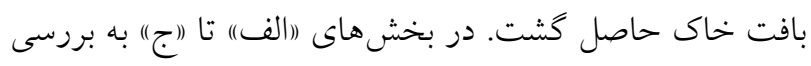
اين معادلات يرداخته مىشود. 
جدول ا. ضرايب معادله تعيين حداكثر قطر بياز رطوبتى براى دبىهاى مختلف بههمراه شاخصهاى آمارى مربوطه

\begin{tabular}{|c|c|c|c|c|c|}
\hline MAD & RMSE & $\mathrm{R}$ & $\mathrm{b}$ & $\mathrm{a}$ & دبى (cm/hr) \\
\hline $1 / 00 K^{k}$ & l/IKF & $0 / 990$ & $0 / M I Y$ & $r q / \Lambda r$ & 10 \\
\hline I/OrV & $1 / T 9 V$ & $0 / 990$ & $\circ / T \wedge \Delta$ & $\mu_{\circ / \Lambda} \circ$ & $\wedge$ \\
\hline $0 / \wedge 01$ & $\circ / V Y_{0}$ & $0 / 999$ & $\circ / \mu \backslash \Lambda$ & TV/OY & 9 \\
\hline ONYG & O/GKT & $0 / 999$ & $\circ / \mu \mid \psi$ & $Y Y / F Y$ & q \\
\hline
\end{tabular}

نشان مى دهد كه روابط ارائه شده $\mathrm{R}$ و $\mathrm{RMSE}<1 / \mathrm{TV}$ براى دبى هاى مختلـف در بافـت يكسـان داراى دقـت مناسـبى خصوصاً براى دبى هاى كمتر مىباشد و اينكه رابطه توانى رابطـه. مناسبى جهت بيان ارتباط بين مقادير زمان با مقادير حداكثر قطر بياز رطوبتى شكل گرفته تحت منبـع نقطـهاى مسىباشـد. مقــدار ضريب همبستكى در مطالعه نصسيرى و همكــاران (9)، در بـازه

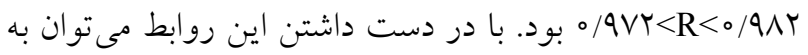
ازاى زمان دلخواه، حداكثر قطر جبهه بيشروى را در زيسر سـطح خـاك يسيشبينسى نمـوده و از رسـيدن آب بـه ريشـه كياهـان، خصوصاً كياهانى كه داراى ريشه يراكنده و بهرن هستند، اطمينان حاصل نمود.

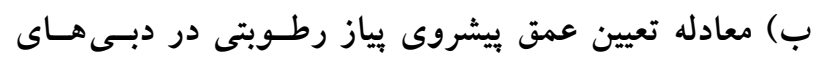
مختلف براى تعيين معادله عمـق ويشـروى بيــاز رطـوبتى در دبسىهـاى مختلف، مقادير عمق بيشروى جبهه رطـوبتى خـاى حاصـله از

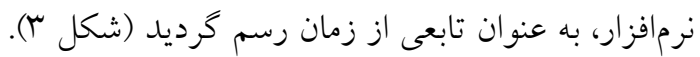
شكل (r)، صعودى بودن عمق بياز رطـوبتى تشـكيل يافتـه

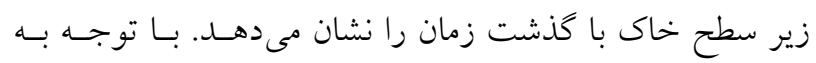
شكل، در زمان ثابت، با افـزايش مقــدار دبسى، شـاهد بيشـروى بيشتر جبهه رطوبتى بهصورت عمودى در خـاى خــواهيم بـود.

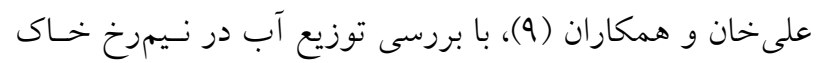

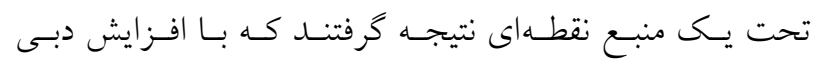
قطرهجهان و حجم آب آبيـارى، عمـق جبهـهـ رطـوبتى افـزايش مى يابد. نتايج نصيرى و همكاران (9) نيز مشـابه نتـايج حاصـله
نسبت به زمان را نشان مىدهد. اين نتايج مشابه نتايج نصسيرى و همكاران (9) مى باشد. ايشان به اين نتيجـه رسـيدند كـه انـدازه تغييرات بيشروى افقى زير قطرهجهان با افزايش ديريـايى زمـان

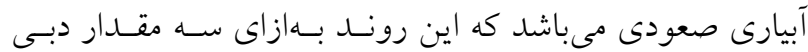
كاربردى در مطالعه آنها مشهود بود. همجنين ايشان بيان داشـتند كه مقدار دبى بالاتر، بيشروى افقى بيشترى را بههمـراه دارد. بـا توجه به شكل (Y)، ملاحظه مى شود كه براى همه دبى هاى مورد مطالعه، شدت بيشروى قطر بياز رطوبتى در ابتــا زيـاد بـوده و سبس رفته رفته با كذشت زمان كاهش مى يابد كه اين امر مشابه با نتيجه رحيم زادكان (Iآ) مىباشد. شكل (Y) نشـان از ارتبـاط تـوانى مقـادير زمـان بـا مقــادير حداكثر قطرى كه جبهه رطوبتى در زير خـاك بـراى دبسىهـاى مختلف ايجاد مى كند دارد. بنابراين بهترين معادله منحنى برازش يافته بر آن به شكل كلى زير خواهد بود: $\mathrm{d}=\mathrm{at}{ }^{\mathrm{b}}$

كه در رابطه [1]، d مقدار حداكثر قطر جبهه رطـوبتى (cm)،

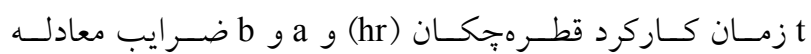
مىباشند؛ اين ضرايب توسط برازش بهترين منحنى به دادههـاى حداكثر قطر برازش يافته نسبت به زمان (رابطـه تـوانى در ايسن مطالعه) حاصل مىشوند. براى تأييد صحت مطالب بيان شـده و مناسب بودن منحنى برازشى، كاربرد شاخص هاى مخلف آمارى

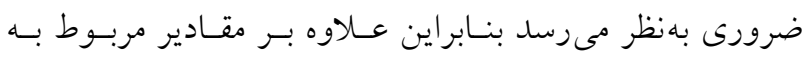
ضرايب معادله، مقادير شاخص هاى آمارى مربوط به هر معادلـه نيز در جدول (1) آورده شده است.

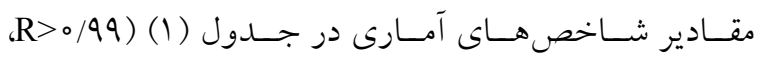




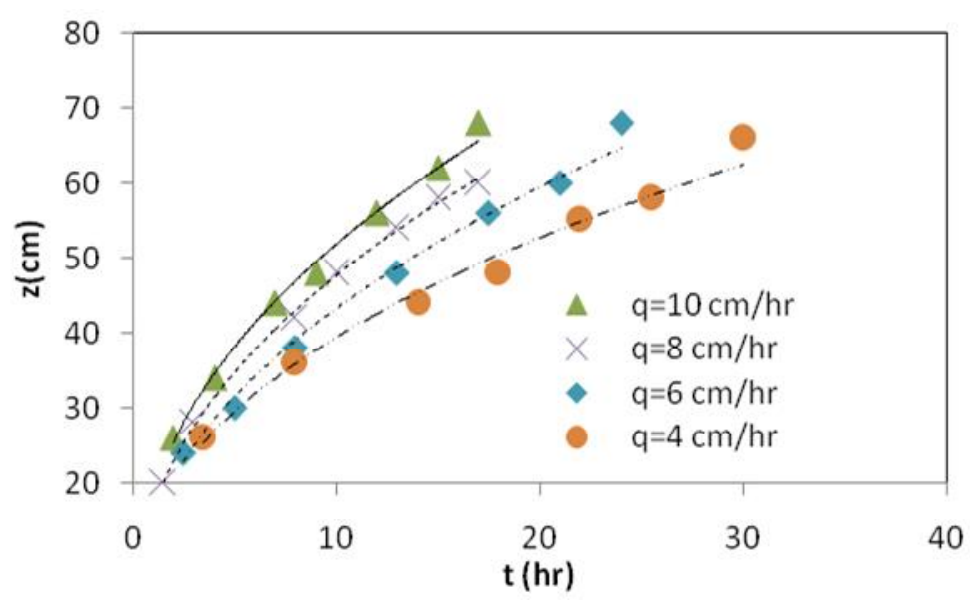

شكل r. تغييرات عمق بياز رطوبتى نسبت به زمان براى دبىهاى مختلف

جدول r. ضرايب معادله تعيين عمق يياز رطوبتى براى دبىهاى مختلف بههمراه شاخصهاى آمارى مربوطه

\begin{tabular}{|c|c|c|c|c|c|}
\hline MAD & RMSE & $\mathrm{R}$ & $\mathrm{f}$ & e & دبى (cm/hr) \\
\hline$\circ / \Lambda \wedge \circ$ & I/Irr & $0 / 99 \mathrm{~V}$ & o/fyt & $11 / 9 V$ & 10 \\
\hline -NTS & - $/ 094$ & $0 / 999$ & $\circ / 4 \Delta Y$ & $19 / V^{4}$ & $\wedge$ \\
\hline $1 / 1 \circ V$ & 1/DQr &.$/ 990$ & $0 / 49$. & $14 / 91$ & 4 \\
\hline $1 / 1 \circ x^{x}$ & I/VVY & $0 / 991$ & $0 / 419$ & $10 / 10$ & r \\
\hline
\end{tabular}

مى توان با اطمينان از اين قبيل معادلات جهت تعيين ابعـاد بيـاز

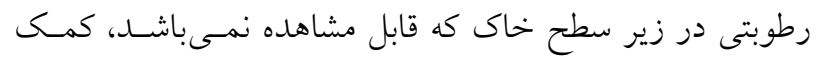
كرفت و در مدت زمان خاصى مقدار عمق جبهـهـ رطـوبتى زيسر يكى قطرهجان را تخمين زد. البته نبايد از نظر دور داشـت كـهـ معادلات حاصله براى بافـت خاصسى از خـاك بـوده و احتمـالاً

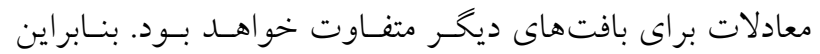

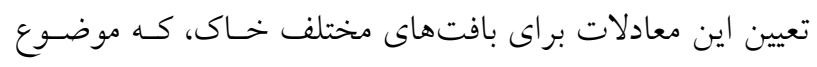
بخش بعدى است، ضرورى بهنظر مىرسد.

ج) معادله تعيين حداكثر قطر يـيـاز رطـوبتى و عمـق آن در بافتهاى مختلف تغييرات مقادير حداكثر قطر و عمق خيسشدكى در محوطه زير

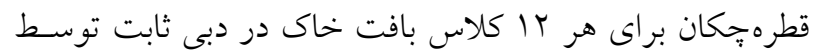

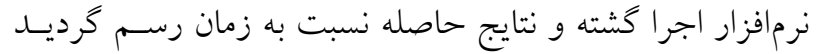

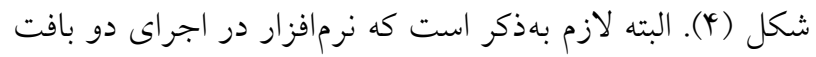

بود. با توجه به شـكل (r)، ملاحظـه مسىشـود كـهـ بـراى همـه دبىهاى مورد مطالعه، شدت افزايش عمق يياز رطوبتى در ابتـدا زياد بوده و سبس رفته رفته با كذشـت زمـان كـاهش مسى ميابــ. نتايج حاصله مشابه نتايج رحيمزادكان (II) بود. با توجه به ايسن

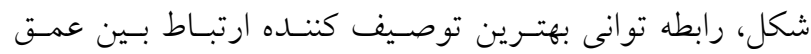

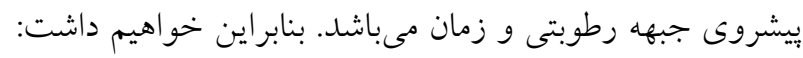
$z=e t^{f}$ كه در اين رابطـه، Z مقــدار عمـق بيشــروى جبهـهـ رطـوبتى ضـ ايب معادلـه

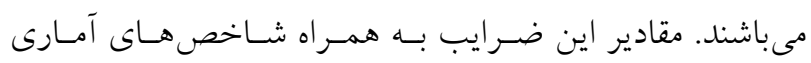
مربوطه در جدول (Y) آمده است.

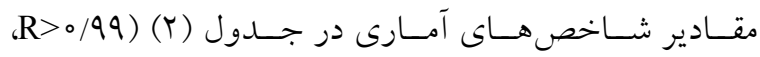
RMSE<1/N/ نشان از دقـت بـالاى معـادلات حاصله جهت تعيين عمق بياز رطوبتى تحت منبع نقطهاى با يك

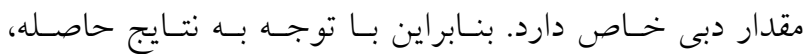



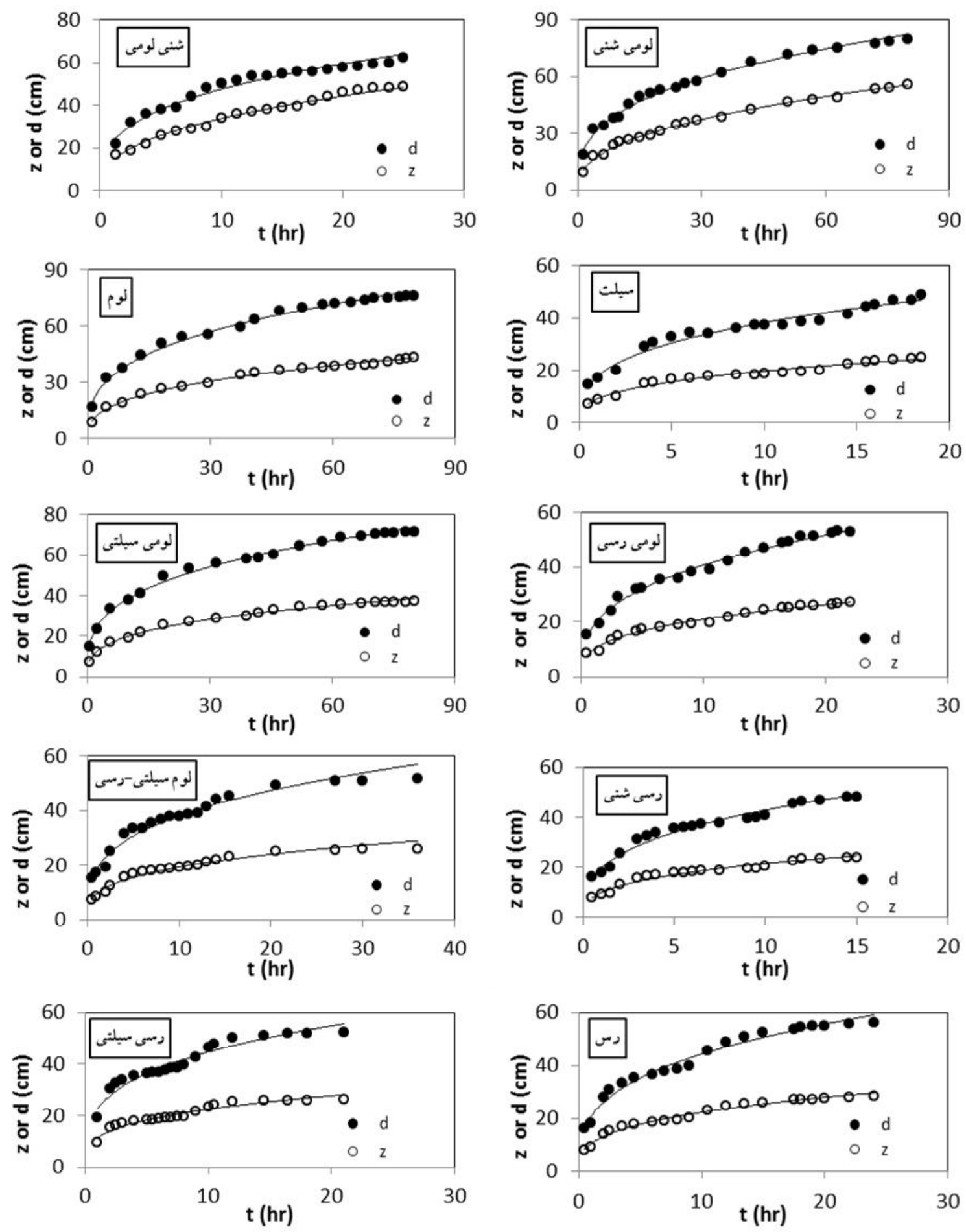

شكل f. تغييرات حداكثر قطر بياز رطوبتى و عمق آن نسبت به زمان در بافتهاى مختلف خاك (نقاط، نشاندهنده مقادير حاصله از نرمافزار و خطوط، نشاندهنده بهترين منحنى برازش يافته مىباشد) 
جدول r. ضرايب معادلات تعيين عمق و حداكثر قطر بياز رطوبتى براى بافتهاى مختلف به همراه شاخصهاى آمارى مربوطه

\begin{tabular}{|c|c|c|c|c|c|c|c|c|c|c|}
\hline \multicolumn{2}{|c|}{ MAE } & \multicolumn{2}{|c|}{ RMSE } & \multicolumn{2}{|c|}{$\mathrm{R}$} & \multicolumn{2}{|c|}{ ضرايب معادله z } & \multicolumn{2}{|c|}{ ضر ايب معادله d } & \multirow[b]{2}{*}{ بافت } \\
\hline deمادله & Zمعلم Z & deمادله & Zمادله & deمادله & Zعادله & $\mathrm{i}$ & $\mathrm{j}$ & g & $\mathrm{h}$ & \\
\hline $1 / 799$ & $\circ / 9 \uparrow V$ & $1 / \wedge V_{0}$ & $1 / 091$ & $\circ / 9 \wedge 9$ &.$/ 994$ & $|r / \Lambda|$ & $0 / \mu \wedge$ & $T r / \Delta Q$ & $0 / \mu Y \mu$ & شنىلومى \\
\hline $1 / 1 \wedge V$ & O/NAI & $1 / 9 \circ 9$ & $0 / 199$ & $0 / 999$ & $\circ / 991$ & $9 / 440$ & $\circ / 4 \circ 4$ & $|N / N|$ & ( ) & لومىشنى \\
\hline I/ITV & ०/VqV & $1 / 491$ & $\circ / N T \Lambda$ & $0 / 999$ & $\circ / 99 V$ & $9 / \pi T \Delta$ & $\circ / T O 1$ & $1 N / 4 T$ & ( ) & لوم لوم \\
\hline $1 / 190$ & $\circ / A V_{0}$ & $1 / 991$ & $0 / \wedge 99$ &.$/ 9 \wedge 4$ & $\circ / 9 \wedge \Delta$ & $9 / 049$ & $\circ / \mu T V$ & IV/AT & ( ) & سيلت \\
\hline $1 / \circ \circ 0$ & o/vaY & $1 / 790$ & -NYA & $\circ / 99 V$ & $\circ / 99 V$ & $9 / 49 V$ & $0 / 419$ & $1 / 199$ & 0 MIr & لومىسيلتى \\
\hline$\circ / 910$ & $\circ / V D Q$ & $1 / / 41$ & $\circ / N I T$ & $0 / 990$ & $\circ / 99 Y$ & $9 / \mathrm{VQ \Lambda}$ & 每 & $|N / \mu|$ & $0 / M Y 4$ & لومىرسى \\
\hline $1 / r \circ r$ & o/QTr & $r / Q H$ & I/AT & $\circ / 9 \wedge \mu$ & $\circ / 9 \mathrm{VA}$ & $9 /$ Tar & $0 / \mu 19$ & $1 N / \Delta D$ & ( & لومسيلتى \\
\hline $1 / 149$ & o/AץA & $1 / 0 / 1$ & $\circ / \Lambda \vee \wedge$ & $\circ / 919$ & $\circ / 9 \wedge r$ & $9 / 191$ & $0 / \mu \Lambda$ & $19 / \mathrm{VV}$ & $0 / \mu r 4$ & رسىشنى \\
\hline $1 / r V 4$ & $\circ / 9 \vee 9$ & $r / 114$ & $1 / 1 \circ r$ & $0 / 999$ &.$/ 991$ & $|1 / r|$ & $0 \mu \circ 1$ & $r r / 49$ & $0 / r q V$ & رسىسيلتى \\
\hline $1 / r 9 K$ & $\circ / \wedge 9 \vee$ & 1/Arr & o/AQr & $0 / 919$ & $\circ / 990$ & $10 / 01$ & $0 /$ TYG & $r \circ / N Q$ & $0 /$ MY & رس \\
\hline
\end{tabular}

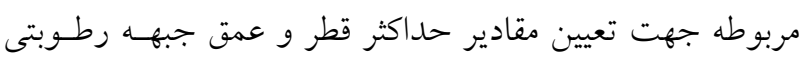

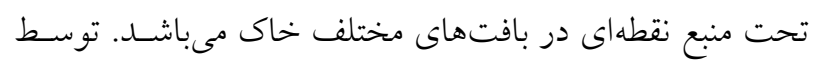

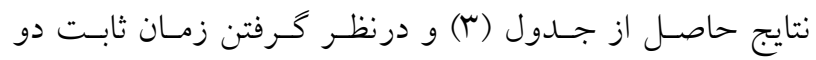

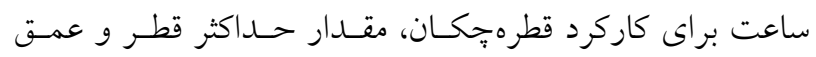

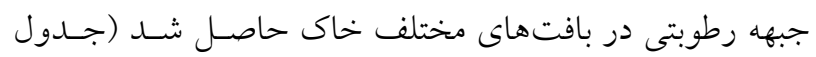

با توجه به جدول (Y)، مقدار حداكثر قطر جبهه رطوبتى بـا فرض دو ساعت كاركرد قطره:كان در همه بافتها، بـهترتيـب

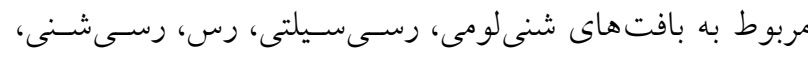

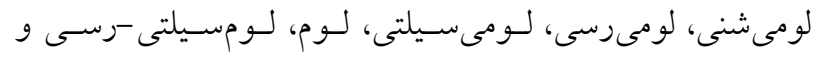
سيلت مى باشد. اكر جاى بافتهاى رسى شنى و لومى شنى با هم عوض شود، همين ترتيب را براى عمق جبهه بيشروى خـواهيم داشت.

\section{نتيجه گيرى}

افزايش سرعت محاسبه كرها و نيـز افزايش قابليـت مـدلهــاى

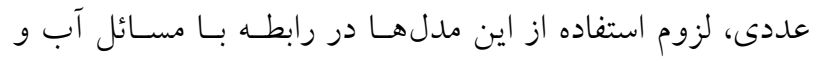

خاك شن و لومشنى -رسى ناتوان بود و نتاج معقولى ارائه نداد. با توجه به شكل (Y) مشخص است كه در همه بافت ها، مقسادير

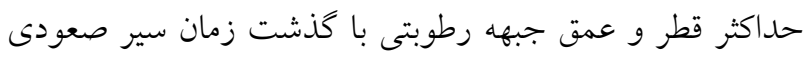

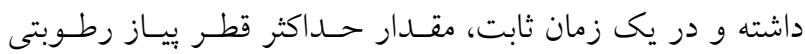
تشكيل يافته تحت منبع نقطهاى بيشتر از عمق بوده است. شـكل

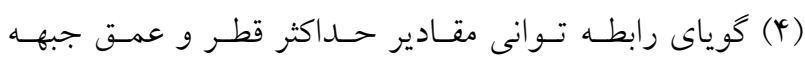
رطوبتى با مقادير زمان است. بنابر اين روابط حاصسله از بهتـرين برازش روى منحنى مربوطه به دو شكل زير خواهد بود: $\mathrm{d}=\mathrm{g} \mathrm{t}^{\mathrm{h}}$ $z=i t^{j}$ كه در اين روابط، d حداكثر عمق جبهه رطـوبتى بـراى هـر بافت خاك در دبى ثابت (cm)، z مقـدار عمـق ييشـروى جبهـهـ رطوبتى براى هر بافت خاك در دبى ثابت (cm)، أ زمان كاركرد

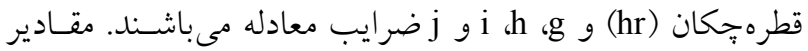

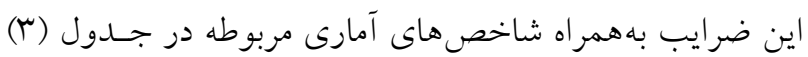

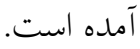

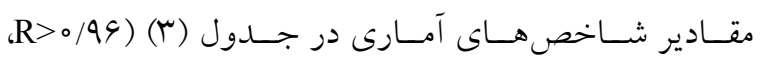
RMSE<r/T و RAD 


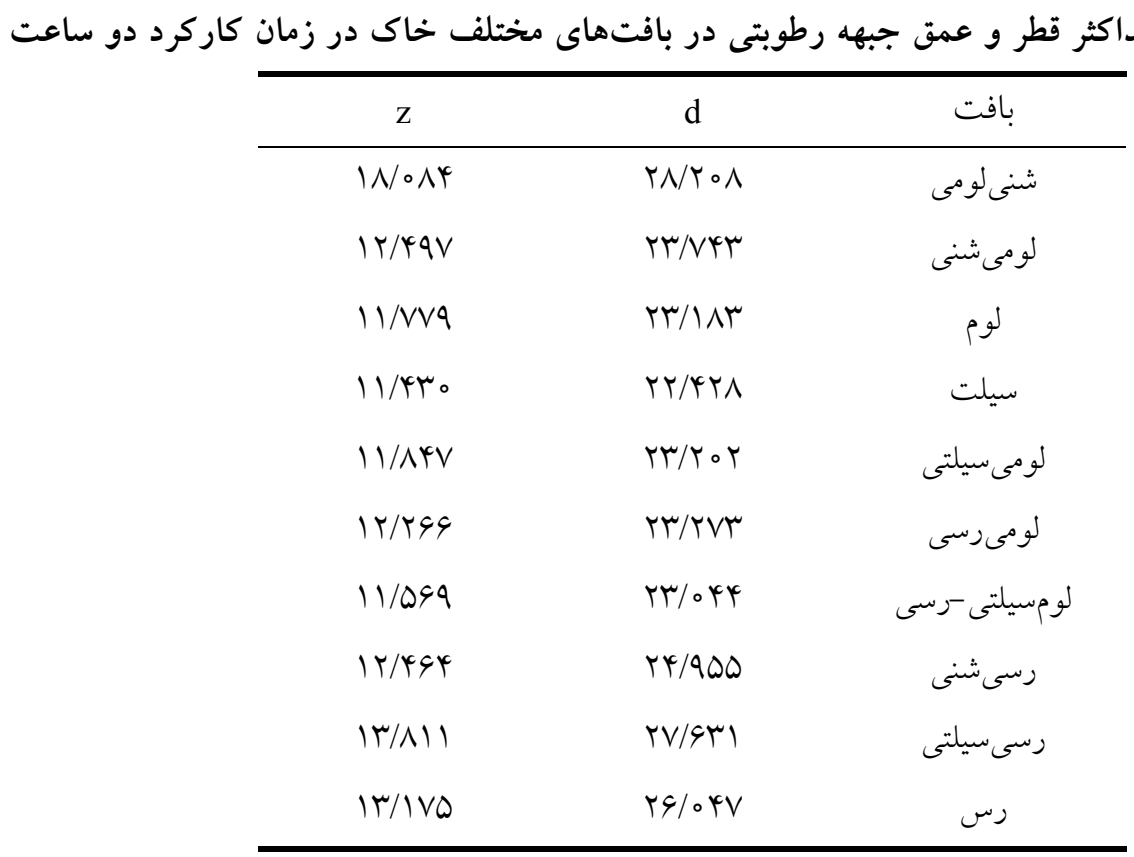

ارائه شده توسط افرادى مثل شوارتزمن و زور (YT)، ميرزايسى و همكاران (ه)، يُنكگى و آخوندعلى (Y)، ساده بودن آنها و وابسته بودن آنها تنها به يك يُرامتر (زمان) مىباشد. نتايج شاخص هاى آمارى مربوط به اين معادلات نشاندهنده دقت بـالاى معـادلات حاصله بود. بنـابراين از جنسين معـادلاتى مسى تـوان در طراحسى سامانهاى آبيارى قطرهاى بهره كرفت.

خاك را آشكارتر مى سازد. نرمافزار HYDRUS-rD يكى از اين مدلهاست كه بر اساس بيان محققان، نتـايج قابـل قبـولى ارائسه

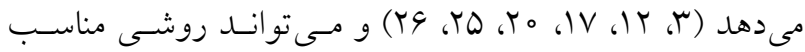
جهـت مــل نمـودن ابعـاد جبهـهـ رطـوبتى شـكل كرفتـه زيـر قطره:جان باشد.

برقرارى رابطه توانى بين نتــايج حاصـل از نـرمافـزار بــراى حداكثر عمق و جبهه رطوبتى در زمانهاى مختلف، امكان ارائسه معادلاتى ساده جهت تعيين حداكثر قطر و عمق جبهـهـ رطـوبتى را فراهم نمود. مزيت اصلى اين معسادلات نسـبت بـه معسادلات

\section{منابع مورد استفاده}

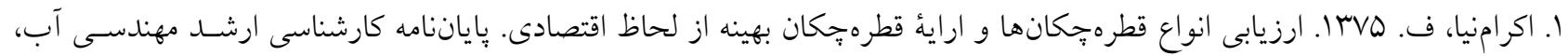
دانشكده كشاورزى، دانشكاه تهران.

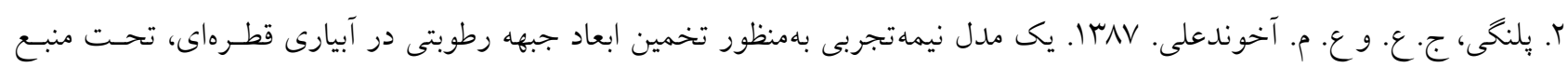

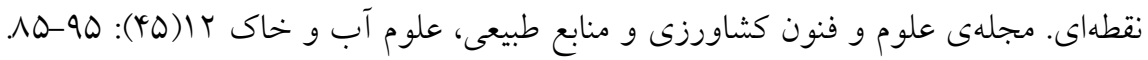

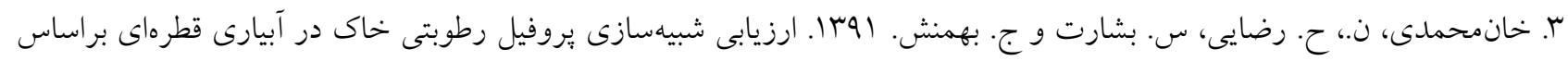

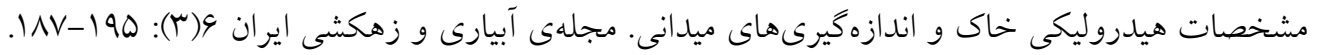




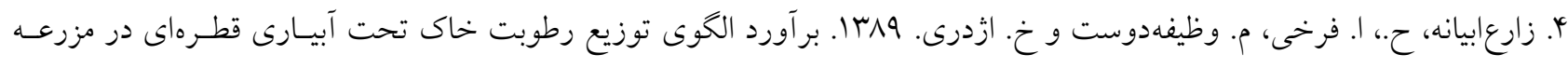

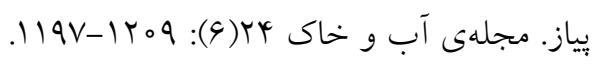

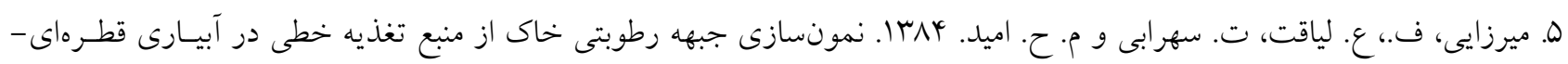

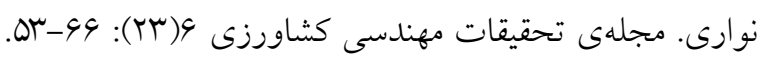

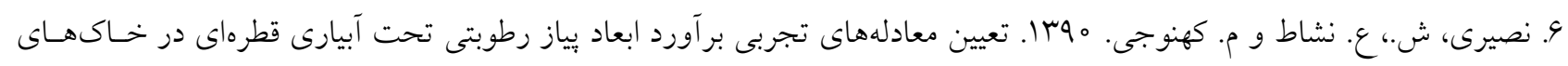

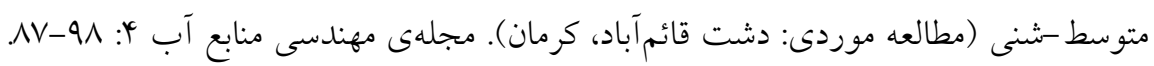

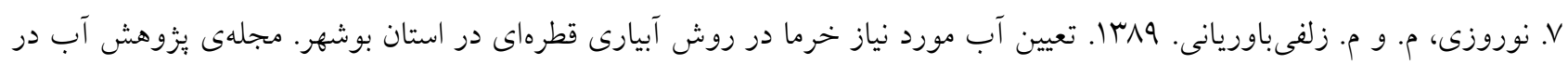

$$
\begin{aligned}
& \text { كشاورزى זץ(1): }
\end{aligned}
$$

8. Adeboye, O. B. and M. O. Alatise. 2007. Performance of probability distributions and plotting positions in estimating the flood of River Osun at Apoje Sub-basin, Nigeria. Int. J. Agr. Eng. 9: 1-21.

9. Alikhan, A., M. Yitayev and W. Warrick. 1996. Field evaluation of water and solute distribution from a point source. J. Irrig. Drain. Engin. 122: 221-227.

10. Angelakis, A. N., D. E. Rolston, T. N. Kadir and V. N. Scott. 1993. Soil-water distribution under trickle source. J. Irrig. Drain. Eng. 199: 484-500.

11. Assouline, S. 2002. The effects of microdrip and conventional drip irrigation on water distribution and uptake. J. Soil Sci. Soc. Am. 66: 1630-1636.

12. Ben-Gal, A., N. Lazarovitch and U. Shani. 2004. Subsurface drip irrigation in gravel-filled cavities. J. Vadose Zone 3: 1407-1413.

13. Cook, F. J., P. J. Thorburn, P. Fitch and K. L. Bristow. 2003. Wet Up: a software tool to display approximate wetting pattern from drippers. J. Irrig. Sci. 22: 129-134.

14. Cook, F. J., P. Fitch, P. J. Thorburn, P. B Charlesworth and K. L. Bristow. 2006. Modelling trickle irrigation: comparison of analytical and numerical models for estimation of wetting front position with time. J. Environ Model Soft 21: 1353-1359.

15. Cote, C. M., K. L. Bristow, P. B. Charlesworth, F. J. Cook and P. J. Thorburn. 2003. Analysis of soil wetting and solute transport in subsurface trickle irrigation. J. Irrig. Sci. 22:143-156.

16. Gardenas, A., J. W. Hopmans, B. R. Hanson and J. Simunek. 2005. Two-dimensional modeling of nitrate leaching for various fertigation scenarios under microirrigation. J. Agric. Water Manage. 74: 219-242.

17. Kandelous, M. M. and J. Simunek. 2010. Numerical simulations of water movement in a subsurface drip irrigation system under field and laboratory conditions using HYDRUS-2D. J. Agr. Water Manage. 97: 1070-1076.

18. Li, J., J. Zang and M. Rao. 2004. Wetting patterns and nitrogen distributions as affected by fertigation strategies from a surface point source. J. Agr.Water Manage. 67: 89-104.

19. Mmolawa, K. and D. Or. 2003. Experimental and numerical evaluation of an analytical volume balance model for soil water dynamics under drip irrigation. J. Soil Sci. Soc. Am. 67:1657-1671.

20. Provenzano, G. 2007. Using HYDRUS-2D simulation model to evaluate wetted soil volume in subsurface drip irrigation systems. J. Irrig. Drain. Eng. 133: 342-349.

21. Rahimzadegan, R. 1977. Water movement in field soil from a point source. Master. Degree Thesis, Agricultural and Irrigation Engineering, Faculty of Agriculture, Utah State University.

22. Schwartzman, M. and B. Zur. 1986. Emitter spacing and geometry of wetted soil volume. J. Irrig. Drain. Eng. 112: 242-253.

23. Shabri, A. 2002. A comparison of plotting formulas for the Pearson type Ш distribution. J. Teknol. 36: 61-74.

24. Simunek, J., M. Sejna and M. Th. Van Genuchten. 2006. The HYDRUS software package for simulating two- and three-dimensional movement of water, heat, and multiple solutes in variably-saturated media. Technical Manual, Version 1. PC Progress, Prague, Czech Republic.

25. Siyal, A. A. and T. H. Skaggs. 2009. Measured and simulated soil wetting patterns under porous clay pipe subsurface irrigation. J. Agr. Water Manage. 96: 893-904.

26. Skaggs, T. H., T. J. Trout, J. Simunek and P. J. Shouse. 2004. Comparison of HYDRUS-2D simulations of drip irrigation with experimental observations. J. Irrig. Drain. Eng. 30: 304-310.

27. Thabet, M. and Kh. Zayani. 2008. Wetting patterns under trickle source in a loamy sand soil of south Tunisia. Am. Euras. J. Agric. Environ. Sci. 3: 38-42.

28. Yahaya, A. S., C. S. Yee, N. A. Ramli and F. Ahmad. 2012. Determination of the best probability plotting position for predicting parameters of the Weibull distribution. Int. J. Appl. Sci. Technol. 2: 106-111. 


\title{
Empirical simulation of wetting pattern in different soil texture
}

\author{
N. Khanmohamadi and S. Besharat ${ }^{1^{*}}$
}

(Received: May 17-2014; Accepted : April 9-2016)

\begin{abstract}
Accurate design of drip irrigation systems requires sufficient understanding of horizontally and vertically distribution of water flow in soil and modeling the wetting pattern dimensions created under the drip source. Field and laboratory activities are not suitable for this purpose considering their time and financial constraints and it is necessary to apply accurate software for determination of several equations in different situations. This research aimed to present simple models for calculation of wetting pattern dimensions in different discharges and structures in drip irrigation system. For this purpose, HYDRUS-2D model was implemented for four discharges in the same soil texture and different soil textures in the same discharge. The values obtained from running the software such as depth and maximum diameter of wetting pattern have been fitted with time values and corresponding equations were obtained. The results of statistical indices for all obtained equations $(\mathrm{R}>0.96, \mathrm{RMSE}<2.12$ and $\mathrm{MAD}<1.38)$ represent suitable accuracy of corresponding equations in determination of pattern dimensions under the drip source. The results also showed that Loamy Sand and Silt textures, respectively, have maximum and minimum depth and wetting pattern diameter.
\end{abstract}

Keywords: drip irrigation, HYDRUS-2D model, wetting pattern dimensions.

1. Dept. of Water Eng., Faculty of Agr., Univ of Urmia., Urmia, Iran.

* Corresponding Author, Email: s.besharat@urmia.ac.ir 